\title{
Information and Measuring System for Ensuring and Monitoring Environmental Safety
}

\author{
Tyurina Marina \\ Kazan National Research Technical University named after \\ A.N. Tupolev Kazan, Russia \\ turina_m@mail.ru \\ Zaripova Rimma \\ Kazan State Power Engineering University \\ Kazan, Russia \\ zarrimma@mail.ru
}

\author{
Porunov Alexander \\ Kazan National Research Technical University named after \\ A.N. Tupolev \\ Kazan, Russia \\ porunov_aa@mail.ru
}

Gaynetdinova Alsu

Kazan Cooperative Institute

Kazan, Russia

alsu.doc@mail.ru

\author{
Kosulin Valery \\ Kazan State Power Engineering University \\ Kazan, Russia \\ valerakosulin@rambler.ru
}

\begin{abstract}
Monitoring of environmental dynamics parameters is largely necessary for monitoring and ensuring environmental safety in regions and industrial zones of high risk of man-made disasters, this is especially important for the territories adjacent to the Silk Road. The paper presents the results of the development of information-measuring system for ensuring and monitoring environmental safety, based on measuring the kinematic parameters of air flows, parameters of its gas composition and parameters of the atmosphere. The approach presented in the paper will allow creating a system of environmental safety control, which allows carrying out a calculated assessment of the impact of man-made disasters and permanent phenomena that affect the environment.
\end{abstract}

Keywords: component, formatting, style, styling

\section{INTRODUCTION}

The idea of the new Silk Road is a global concept of the new pan-Eurasian transport system for the movement of goods and passengers by land [1,2], which runs from China through Kazakhstan, Russia and several other countries to Europe [3]. It is important to note that in addition to the benefits and advantages of the project, both economic and geopolitical, there are a number of environmental risks. The risks that may arise in the process of formation and operation of the infrastructure of the economic belt along the Silk Road can be divided into three groups: natural-ecological, technogenicecological and social-ecological.

Environmental problems are relevant all over the world, in countries and regions, and only in varying degrees of severity. In order to continue the direction of the new Silk Road for regional cooperation between the countries, it is necessary to take into account the issues of environmental security between the countries [4]. This is because the problem of increasing the concentration of greenhouse gases and harmful emissions into the atmosphere is increasing every year. Air pollution is due to the possible continuous development of industry, increasing the intensity of transport, which is due to the economic growth of cities in the world adjacent to the Silk Road. Hence, it should be taken into account that the construction of the economic corridor of the Silk Road, in turn, can lead to an increase in greenhouse gases and other emissions into the atmosphere. The main greenhouse gases [5] are carbon dioxide (CO2), methane (CH4), nitrous oxide (N2O), tropospheric ozone $(\mathrm{O} 3)$ and water vapor $(\mathrm{H} 2 \mathrm{O})$. There are also a number of other greenhouse gases of purely anthropogenic origin such as halogenocarbons (e.g. trichlorofluoromethane, $\mathrm{CFCl} 3$ ).

Among the main technogenic and environmental risks, taking into account the contribution to the atmosphere, accidental emissions of harmful chemicals along the land routes associated with the new Silk Road can be distinguished. The creation of infrastructure and the construction of new 
highways, Railways, gas and oil pipelines can complicate the environmental situation in the cities along the Silk Road, as emissions from transport pollute the air and lead to an increase in the incidence of the population. The emissions of enterprises of various industries and transport contain a large number of different harmful impurities. Sulfur dioxide (SO2), dust, carbon monoxide (CO), nitrogen oxides (NO, NO2) enter the atmosphere from almost all sources of emissions. Only thermal power plants are the source of almost half $(45 \%)$ of the total amount of sulfur compounds entering the air basin. When fuel is burned, carbon monoxide $\mathrm{CO}$, nitrogen oxides and unburned solids in the form of ash and soot are also released into the atmosphere in large quantities. In much smaller quantities, sodium chloride and magnesium, iron oxides, vanadium, Nickel and calcium oxides, mercury and a number of other substances that appear when burning both solid and liquid fuels can be emitted. Studies [6-9] shown that even with constant volumes and composition of industrial and transport emissions a result of the influence of meteorological conditions air pollution levels can vary several times. Taking into account this influence is important in the preparation of documents with requirements for air quality $[10,11]$, the development of air protection measures, as well as in forecasting the level of pollution along the Silk Road.

\section{METHODS}

Thus, in the complex of measures to ensure environmental safety, it is necessary to highlight the problem of improving methods and means of assessing the dynamic and thermophysical parameters of the atmosphere, determining the conditions of dissipation of harmful substances in industrial areas of increased technogenic risk adjacent to the Silk Road. Solving the problem of environmental control of zones of high technogenic risk requires the creation of distributed environmental monitoring systems along the Silk Road. This is achieved by placing environmental monitoring posts in the immediate vicinity of the territory of the Silk Road. The existing posts of ecological meteorological control practically solve the problem of tracking the dynamics of only climatic factors, including the following sensors for environmental control: temperature, humidity, wind speed and direction, pollution, gamma radiation (radiation radiation), gas analyzers (stationary and operating in automatic mode), etc. [12-14]. While the range of tasks of environmental monitoring should also include the control of parameters that determine the evolution of emissions of harmful substances. Many monitoring systems include cartographic and thematic databases on industrial enterprises of the region (city), containing data on the structure and volume of their emissions and discharges of harmful substances into the environment. Such information is usually used in identifying possible adverse environmental situations, as well as in making decisions and choosing measures to reduce the consequences of the impact of man-made disasters.

A significant impact on these processes having crossborder mass-transfer in significant-defined variation of the kinematic parameters of the wind in the atmospheric surface layer and in which change not only the climate (meteorological) characteristics (temperature, humidity, pressure) of ambient air, but also the composition, concentration and speed of its change in the wake of clouds of pollutants in the air. This makes it particularly urgent to create a system of monitoring the dynamics of the atmosphere according to the above parameters within the zones of the Silk Road. This will allow positioning and distribution of harmful emissions, as well as their dissipation. The solution of these problems requires not only the assessment of the maximum permissible concentrations of harmful substances, which is based on the data of gas analysis, but also it is necessary to solve the problem of forecasting the dynamics of changes in MPC in time and space (along the trajectory of the Silk Road) by analyzing the kinematic parameters of the atmosphere.

The objectives of environmental monitoring require the creation of multi-channel information tools and environmental control, in which you can select the channels to measure the dynamics of the wind (speed and direction), channels thermalgas-dynamical parameters of the atmosphere (pressure, temperature and speed changes) and channels gas analysis (concentrations of nitrogen oxide, carbon monoxide, hydrocarbons, sulfur dioxide and hydrogen sulfide). The measurement of these parameters is proposed to perform in the framework of two-circuit measurements. The first circuit allows the measurement of meteorological parameters, and the second circuit is designed for gas analysis of the atmosphere.

Existing means of wind dynamics parameters, such as anemotachometric, weathervane and other mechanical meters of kinematic parameters of air masses motion have limited functionality due to the dependence of their characteristics on temperature, pressure, humidity and other parameters and properties of the atmosphere changing in the course of their operation. In addition, they have low mechanical reliability and limited accuracy [11]. More effective are the methods and means based on a combination of flow aerometric, ion-label and jet-convective measuring channels.

In the system of technical means of identification of parameters of wind processes for a long time the dominant position was occupied by meters based on power (aerodynamic) and thermal processes [15]. However, in recent years, thanks to great achievements in electronic engineering and technology, increasingly used are meters of kinematic parameters of wind processes, the output signal of which is formed as a result of recording the time interval of the socalled "mark" (or "marker"), which is a disturbance created in a moving medium by force, electrical or chemical influences.

One of the most important and fundamental requirements for measuring wind parameters is to ensure omni-directional measurements in the azimuthal plane. The problem of measuring the direction of the wind speed vector, the operating range of which is 0-180 angles. hail at wind speeds of $3 \ldots .5 \mathrm{~m} / \mathrm{s}$, and the problem of measuring of the parameter that determines the dynamics of the atmosphere (the rate of change in atmospheric pressure) are of great complexity [16].

Implementation of measuring parameters of the wind based on ion-label converters that meet this requirement are possible through the application of multi-element systems registered electrodes with their integration schemes and connected to the processor unit and the locking by the last 
direction and speed of movement of the label and, consequently, the direction and module of the wind velocity vector in any direction in the azimuth plane.

Another direction of ensuring the requirements of omnidirectional measurement of wind parameters is the creation of multi-channel WRD. The wide possibilities for ensuring the above requirements are opened by the combined use of ion-tagged and jet-convective [17] methods of converting informative signals. The measuring channels implemented on their basis are electronic devices that do not have moving parts, with a fairly simple design and manufacturing technology. This allows you to successfully solve the problems of miniaturization, adaptation of the design to various applications and installation of means for measuring the kinematic parameters of wind, both directly at ground level, and at mobile laboratories and environmental monitoring stations. The output informative signals of ionmeasuring measuring channels is the pulse duration, frequency or directly digital code, which ensures their high noise immunity and ease of pairing with microprocessor processing and indication devices. A wide range of measurements and high metrological characteristics of ion-labeled measuring channels are preserved even when operating conditions change, which allows us to build various environmental monitoring system options on their basis.

\section{RESULTS}

The article presents a variant of the structural construction of the information and measurement system for ensuring and monitoring environmental safety (Fig.1) based on aerodynamic method and jet-convective converters [16-18].

Omni-directional wind receiving device (WRD) (Fig. 2) is achieved through the use of radially arranged receiving tubes of full pressure of a stationary flow-type WRD [18]. On the end surfaces of the cylindrical aerodynamic body are placed coaxially two shielding discs, made in the form of a body of rotation, forming which are close to the contour of the Venturi, and the inner surfaces are facing each other and adjacent to the ends of the aerodynamic body. Between them are placed tubular receivers of full pressure. On the inner surfaces of the shielding discs are radially arranged holes for receiving static pressure, which are connected by pneumatic channels to the static pressure converter.

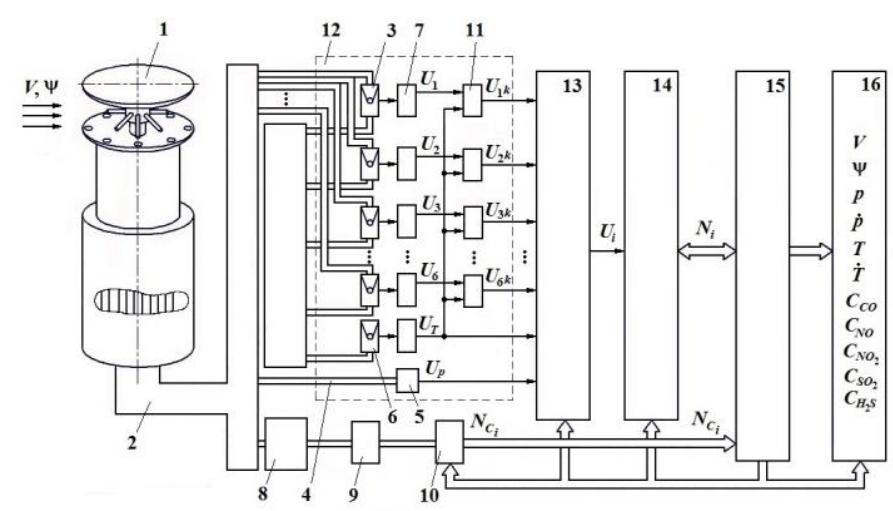

Fig. 1. Block diagram of the system for ensuring and monitoring enviromental safety: 1 - wind receiving device; 2 - pneumatic channel; 3 anemosensitive elements; 4 - channel of atmospheric pressure measurement; 5 - block of formation of an electric signal on absolute pressure; $6-$ compensation converter; 7 - electric measuring circuit; 8 - gas sampler; 9 flow inducer; 10 - multichannel gas concentration measuring converter; 11 analog divider; 12 - electronic block; 13 - switch; 14 - analog-digital converter; 15 - the information-processing device; 16 - means of displaying information

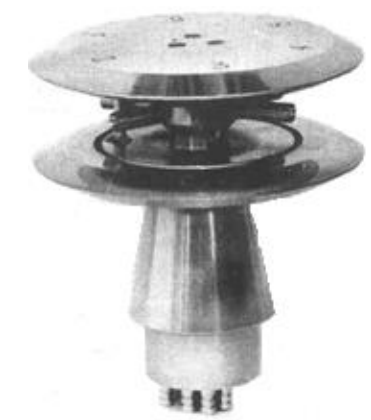

Fig. 2. Wind receiving device

In the proposed version of the structural construction of the system for measuring the parameters of the wind speed vector (Fig. 1), nine measuring transducers of the kind of signal energy (jet-convective transducers) are used to ensure the required accuracy of measuring the wind azimuth, and the ninth is compensation [18]. The output signal of the compensating jet-convective module, located in the same climatic conditions as the measuring ones, is used in the information-processing device to correct the additive and multiplicative components of the temperature error.

The primary pneumatic signals generated in the windreceiving device are fed into the pneumatic channels containing the anemosensitive elements of the jet-convective transducers modules (Fig. 3). In the channels of the modules, under the influence of the oncoming airflow, a pressure drop occurs, which leads to the overflow of air with a flow rate, which will later be converted into a proportional electric the signal in block of the analog processing. Each of the measuring channels of the omnidirectional system [15] is built on the basis of the principle of structural identity of all measuring channels, made on the basis of jet-convective transducers. The formation of signals according to the climatic parameters of the atmosphere in this variant of structural construction is carried out due to the spatio-temporal 
when condition (3) is satisfied

The numerical value of $\theta$ is determined based on the solution of one of the equations of the form:

$$
\frac{p_{(i-1)}}{p_{i}}=\frac{f(\theta)}{f(-\theta)}
$$
analog processing unit are sent to the multiplexer for sequential transmission to an analog-to-digital converter for further processing. With the ADC, the value of the electric signal, in the form of a code, is supplied to the informationprocessing device for the accumulation, storage and secondary processing of information.

The measurement of the rate of change of atmospheric pressure, perceived by the receiving holes located on the inner surfaces of the shielding discs, is carried out by averaging the static pressure in the averaging chamber. The camera output is communicated with a static pressure sensor pc, the output signal of which is supplied directly $U_{p_{a}}$ and through a differentiator $U_{\dot{p}_{a}}$ to the independent inputs of the multiplexer.

The algorithm for processing and generating the results of measuring the parameters of the wind speed vector (WSV), carried out in the information-processing device, consists of several stages [16]. The first step in processing the array at $i$ (where $i=1 \div 6$ ) pressure values is to find the number of the $i$ th tube. The tube number is used to determine the first approximation of the angular coordinates of the WSV in accordance with the expression

$$
\Psi_{t i}=60^{\circ} \cdot i
$$

Then, a preliminary assessment of the position of the WSV relative to the $i$-th full pressure tube is carried out. To this end, the inequalities are verified:

$$
p_{i-1}>p_{i+1}
$$

or

$$
p_{i-1}<p_{i+1},
$$

where $p_{\mathrm{i}-1}$ and $p_{\mathrm{i}+1}$ are the pressure measured in the total pressure tubes adjacent to the $i$-th tube. The next processing step is to determine the exact value of the angular coordinates of the WSV in the sector of angles:

$$
\theta \in\left[\left(\Psi_{t(i-1)}+\Psi_{t i}\right) / 2, \Psi_{t i}\right]
$$

when condition (2) is satisfied, and in the angle sector:

$$
\left[\Psi_{t i},\left(\Psi_{t i}+\Psi_{t(i+1)}\right) / 2\right]
$$

or

$$
\frac{p_{(i+1)}}{p_{i}}=\frac{f(-\theta)}{f(\theta)}
$$

where $f(-\theta)$ is approximating polynomials of degree $k$, calculated according to the results of preliminary grading of WRD, and having the form:

$$
f(-\theta)=-0,0062 \theta^{3}+0,69 \theta^{2}-0,19 \theta+0,87 .
$$

According to the results of solving equations (7) or (8), the angular coordinate of the wind speed vector (wind azimuth) in the original coordinate system is determined based on the dependence:

$$
\Psi_{x}=\Psi_{\min } \pm\left(\theta_{\max }-\theta_{x}\right) t_{0}
$$

where $\langle+\rangle\rangle-$ before the second term corresponds to condition (2); «-»- corresponds to condition (3).

After determining the direction of the wind speed vector, the pressure value $p_{t}$ corresponding to the vector module is restored. This calculation is carried out in accordance with the following relationship:

$$
p_{t}=p_{i} \frac{f\left(\theta_{0}\right)}{f\left(\theta_{x}\right)}
$$

where $p_{i}$ is the pressure of the $i$-th tube; $f\left(\theta_{0}\right)$ is the value of the function that describes the angular characteristic of each of the «n» total pressure tubes at $\theta_{0}=0$. Then $f\left(\theta_{0}\right)=1,0$ is taken (when calculating the pressures from the full pressure tubes); $f\left(\theta_{\mathrm{x}}\right)$ is value of the function for the current angular position of the airspeed vector.

The next step is to find the numerical value of the WSV module $U$ according to

$$
U=\sqrt{2\left(p_{t}-p_{s}\right) g R T / p_{s} \chi}
$$

where $p_{t}$ is total pressure; $p_{s}$ is static pressure; $\chi$ is the pressure recovery coefficient determined by the design features of the WRD; $g$ is acceleration of gravity; $R$ is universal gas constant; $T$ is air temperature. 
through a pneumatic commutator controlled by a signal $U_{m 2}$ from block of the information processing. Each of light streams interacts with its radiation receiver, built on a photodiode, coordinated in spectrum with the radiation source.

At the output of the switching circuit of each of the photodiodes, electrical signals are formed, proportional to the concentration of the reference and measured gases, respectively. Further, the signals are transmitted to the signal processing unit, where they are processed in accordance with the Booger-Lambert-Behr law

$$
I_{\lambda}=I_{0 \lambda} \exp \left(-\varepsilon_{\lambda} C l\right)
$$

where $I_{0 \lambda}$ is the incident radiation intensity at a given radiation wavelength $\lambda ; \varepsilon_{\lambda}$ is the energy absorption coefficient at a given wavelength; $C$ is the concentration of the absorbing gas; $l$ is the length of the absorbing gas layer.

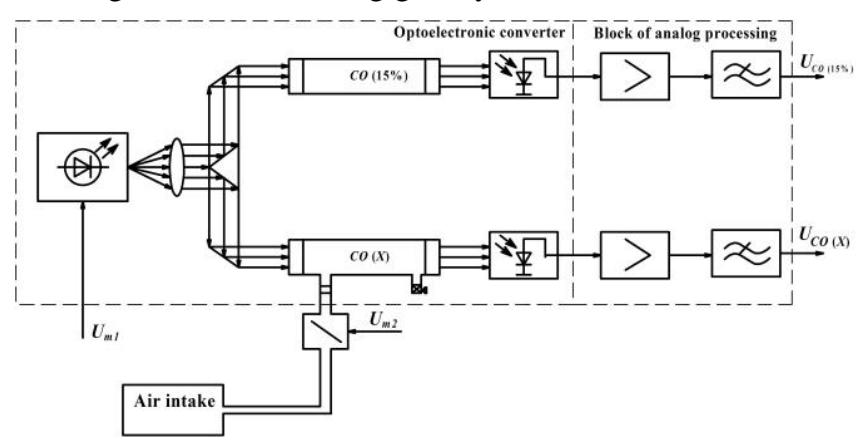

Fig. 4. Functional diagram of $\mathrm{CO}_{2}$ measurement and control channel

\section{SUMMARY}

Thus, the principles and schemes proposed in the work for the construction of an information measuring system for ensuring and monitoring environmental safety are implemented in the form of two circuits. The first of one is used to generate signals determining parameters of statics and dynamics of the surface layer of the atmosphere, and the second one is used to solve the task of identifying parameters of emission of harmful substances and predicting propagation of its trace in the surface layer of the atmosphere. At the same time due to originality of structure principles and structural construction of wind receiving device, excluding movable elements in wind receiving device, measurement range (towards low speeds) is expanded and operational reliability is improved. The originality of the proposed structure principles and structural construction of the system is based on the use of a wind-receiving device that does not contain movable elements. For the first time, we propose the use of an aerodynamic method for measuring the kinematic parameters of airflows to obtain a multi-component pneumatic signal that carries information about the wind speed and direction. This ensures that the gas-sensitive element interacts with the parameters of the air environment. The subsequent conversion of the pneumatic signal into an electric signal is proposed to be carried out, using a jet-convective Converter that has a high sensitivity in the low-speed range. The proposed concept and 
Control," Journal of Sensors, 2017, Article ID 6879748, https://doi.org/10.1155/2017/6879748.

principles for the construction of an information measuring system will provide information on the parameters of the atmosphere: $U$ velocity (from $2 \mathrm{~m} / \mathrm{s}$ to $60 \mathrm{~m} / \mathrm{s}$ ), a azimuth wind $\psi$ (the 360th hail.), atmospheric pressure $p_{a}(760 \pm 30$ of $\mathrm{mm}$ $\mathrm{Hg})$, temperature $T$ air $\left( \pm 60{ }^{\circ} \mathrm{C}\right)$ and the speed of their change and also information on concentration of harmful gases in the atmosphere: carbon monoxide $C O$ (up to $1000 \mathrm{mg} / \mathrm{m}^{3}$ ), nitrogen oxides $N O$ (up to $50 \mathrm{mg} / \mathrm{m}^{3}$ ) and $\mathrm{NO}_{2}$ (up to 20 $\mathrm{mg} / \mathrm{m}^{3}$ ), sulfur dioxide $\mathrm{SO}_{2}$ (up to $100 \mathrm{mg} / \mathrm{m}^{3}$ ) and hydrogen sulfide $\mathrm{H}_{2} \mathrm{~S}$ (up to $50 \mathrm{mg} / \mathrm{m}^{3}$ ). This set of information parameters can be used in decision-making on current environmental conditions at the release location, but also in predicting the impact of the proliferation of the impact of harmful emissions on the environment and is sufficient for the optimization of situational management of ecological security in the zones of location of the Silk Road.

\section{REFERENCES}

[1] M. Hung, T. Chan, "The Belt and Road Initiative - the New Silk Road: a research agenda," Journal of Contemporary East Asia Studies, vol. 7(2), 2018, pp. 104-123, DOI: 10.1080/24761028.2019.1580407.

[2] Y. Li, H.J. Schmerer, "Trade and the New Silk Road: opportunities, challenges, and solutions," Journal of Chinese Economic and Business Studies, vol. 15(3), 2018, pp. 205-213, DOI: 10.1080/14765284.2017.1347473.

[3] A.G. Druzhinin, D. Yawen, "One Belt - One Road Initiative: a window of opportunity for Russia's Western border regions," Baltic Region, vol. 2, 2018, URL: https://cyberleninka.ru/ article/n/one-belt-one-roadinitiative-a-window-of-opportunity-for-russia-s-western-border-regions, doi: 10.5922/2079-8555-2018-2-3.

[4] E.F. Tracy, E. Shvarts, E. Simonov, M. Babenko, "China's new Eurasian ambitions: the environmental risks of the Silk Road Economic Belt, Eurasian Geography and Economics, vol. 58(1), 2017, pp. 56-88, DOI: 10.1080/15387216.2017.1295876.

[5] X. Lu, L. Zhang, L. Shen, "Meteorology and Climate Influences on Tropospheric Ozone: a Review of Natural Sources, Chemistry, and Transport Patterns," Current Pollution Reports, vol. 5, 2019, p. 238. https://doi.org/10.1007/s40726-019-00118-3.

[6] R.S. Zaripova, E.A. Saltanaeva, N.G. Bikeeva, E.V. Priimak, "Development of quality monitoring devices for industrial water in heat supply systems," IOP Conference Series: Earth and Environmental Science, vol. 288, 2019, p. 012129.

[7] W. Wang, "Progress in the impact of polluted meteorological conditions on the incidence of asthma," J Thorac Dis, vol. 8(1), 2016, pp. 57-61, doi:10.3978/j.issn.2072-1439.2015.12.64.

[8] J. Lozano, C. Apetrei, M. Ghasemi-Varnamkhasti, D. Matatagui, J.P. Santos, "5 Sensors and Systems for Environmental Monitoring and
[9] E.G. Dragomir, M. Oprea, "Air Quality Forecasting by Using Nonlinear Modeling Methods. In: Mladenov V.M.," Nonlinear Dynamics of Electronic Systems, vol. 438, 2014, DOIhttps://doi.org/10.1007/978-3-

[10] A. Gayer, Ł. Adamkiewicz, D. Mucha, A. Badyda, "Air quality health indices - Review," Fire and Environmental Safety Engineering, 2018, URL: conferences.org/articles/matecconf/abs/2018/106/ matecconf_fese2018_00002/matecconf_fese2018_00002.html.

[11] A. Morris, R. Barras, Air Quality Meteorology and Atmospheric Ozone, 1978, https://doi.org/10.1520/STP653-EB.

[12] M. Bogdan, "About the Smart Weather Station. Acta Universitatis Cibiniensis. Technical Series, vol. 68(1), 2016, DOI: 10.1515/aucts2016-0006.

[13] M. Nsabagwa, J.S. Otim, R.N. Akol, G. Ninsiima, R. Mwesigye, M. Byamukama, B. Pehrson, "Condition Monitoring for Wireless Sensor Network-Based Automatic Weather Stations," EAI Endorsed Transactions on Internet of Things, 2018 , http://dx.doi.org/10.4108/eai.20-12-2018.156083.

[14] K. Lagouvardos, V. Kotroni, A. Bezes, I. Koletsis, T. Kopania, S. Lykoudis, N. Mazarakis, K. Papagiannaki, S. Vougioukas, "The automatic weather stations NOANN network of the National Observatory of Athens: operation and database," Geosci. Data J., vol. 4, 2017, pp. 4-16, doi: 10.1002/gdj3.44.

[15] M.M. Tyurina, A.A. Porunov, E.V. Panteleeva, N.A. Porunov, "Schematic aspects of development of air signal measurement systems based on jet-convective converters," Materials of the VI International NPK "Modern technologies, materials, equipment and accelerated recovery of qualified personnel potential-key links in the revival of domestic aircraft construction", 2012, pp. 147-153.

[16] Ed. A.A. Porunov, M.M. Tyurina, N.A. Porunov, A.V. Berdnikov, Russian patent for invention No. 2548299 (RF): IPC G01W1/02 system for measuring atmospheric dynamics in the surface layer. // / publ. 20.04.2015, Bul. No. 11.

[17] A.A. Porunov, M.M. Tyurina, "Development and research of jetconvectivetion module based on anemosensitive element," Vestnik KGTU im. A. N. Tupolev, vol. 4, 2013, pp. 113-119. flows on the basis of multi - channel flow receiver and jet-convective converters," Abstract of the thesis for the degree of candidate of technical Sciences, Kazan state technical University. A. N. Tupolev, 2012, p. 24.

[19] K.J. Parkinson, "Carbon Dioxide Infra-Red Gas Analysis: EFFECTS OF WATER VAPOUR," Journal of Experimental Botany, vol. 22(1), 1971, pp. 169-176, https://doi.org/10.1093/jxb/22.1.169.

[20] S. Gersen, V.E. Martijn, P. Visser, A. Mohammad, A. Mokhov, A. Sepman, R. Alberts, A. Douma, H. Levinsky, "Detection of H2S, SO2 and $\mathrm{NO} 2$ in $\mathrm{CO} 2$ at pressures ranging from 1- 40bar by using broadband absorption spectroscopy in the UV/VIS range," Energy Procedia, vol. 63, 2014, pp. 2570-2582, DOI: 10.1016/j.egypro. 2014.11.279. 319-08672-9_46.

[18] M.M. Tyurina, "Multifunctional system for measuring parameters of gas 